\title{
Japanese Species of the Genus Lasconotus (Coleoptera: Zopheridae: Colydiinae), with Description of a New Species from Ishigaki-jima Island, the Ryukyu Islands
}

\author{
Jun-ichi Aoki \\ 3-8-12 Nishi-Azabu, Minato-ku, Tokyo106-0031, Japan \\ E-mail:ja-muck@jcom.zaq.ne.jp \\ (Received 26 May 2017; Accepted 4 December 2017) \\ http://zoobank.org/D46EC3E1-F1B1-4CF1-A16C-50B9336AD033
}

\begin{abstract}
A new species of the genus Lasconotus Erichson, 1845 from Ishigaki-jima Island, Southwest Japan, is described. Lasconotus akitai sp. nov. is compared with the three previously known species of Lasconotus in Japan: L. niponius (Lewis, 1879), L. okadai Aoki, 2011, and L. sculpturatus (Sharp, 1885). The new species is characterized by small body size, large eyes, antennal segments III and IV same in size, four sharp ridges on pronotum, and bubble-shaped sculpture on ventral side of body. A key to the four Japanese Lasconotus-species is also given.
\end{abstract}

Key Words: Colydiinae, Lasconotus, new species, Ishigaki-jima island, Zopheridae.

\section{Introduction}

The genus Lasconotus Erichson, 1845 is one of the largest groups of the subfamily Colydiinae, including more than fifty species in the world, nine species in Asia and three species in Japan (Sharp 1885; Nakane 1963; Narukawa 2000; Aoki 2009a, b, 2011). This genus can be distinguished from other confamilical genera in having parallel-sided elongate body, antennae 11-segmented, forming a club with three terminal segments and four carinae on pronotum.

Recently, an unknown species was collected in Ishigakijima island, the Ryukyu Islands located in the southwestern part of Japan. It is here described as a new and compared with the other three Lasconotus species known from Japan, which are also endemic to the archipelago. A key to the Japanese species of Lasconotus is provided.

\section{Materials and Methods}

Most specimens of the new species were collected by Mr. K. Akita from a standing dead tree. The tree species was undetermined, but it must be one of deciduous trees. Colydiine beetles were ejected from holes of bark beetles by fogging with insecticide (pyrethroid). The beetles dropped on white sheet spread around the dead tree and were picked up with sucking tube and removed to vial containing ethyl acetate. One single specimen was collected by S. Sugimoto using a light trap.

One specimen of each Japanese species of Lasconotus was dissected and mounted with Hoyer's solution on slide glasses for morphological comparison to observe important parts using a microscope of four hundred magnifying power. The main morphological parts investigated in the four species are (1) a form of antennae, especially terminal three segments forming a club, (2) relative size of the third and fourth segments of antennae, (3) size of eyes, (4) shape of pronotum, and (5) surface sculpture of abdomen in ventral side (all illustrated in Figs 1-10).

The type series of the new species is distributed among the collections of the National Museum of Nature and Sci-

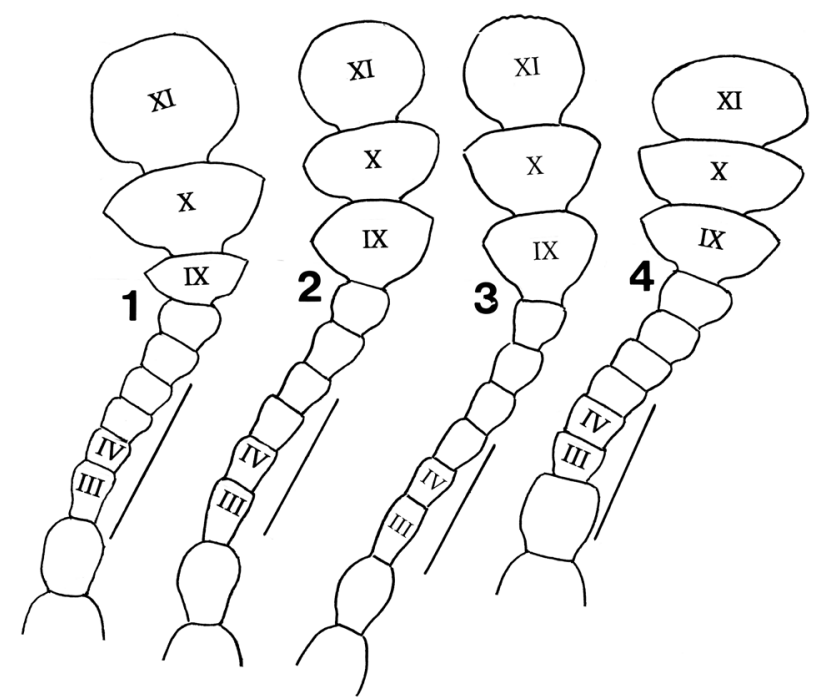

Figs 1-4. Antennae (right side) of the four Japanese species of Lasconotus.-1, L. niponius (Lewis, 1879) (JAC-1); 2, L. okadai Aoki, 2011 (JAC-8); 3, L. sculpturatus (Sharp, 1885) (JAC-11); 4, L. akitai sp. nov. (paratype, NSMT-I-C 200239). Scale bars: $0.1 \mathrm{~mm}$. 
ence, Tsukuba (NSMT), Osaka Museum of Natural History, Osaka (OMNH) and Mie Prefectural Museum, Tsu (MNM). The other Lasconotus specimens used for comparison including those mounted on slides were also deposited in NSMT, receiving temporary registry numbers from JAC-1 to JAC-11.

To express calculated ratios of measurements the following abbreviations are used: PW/PL (width/length of pronotum), EW/PW (elytra/pronotum width ratio), EL/EW (ratio length/width of elytra), and EL/PL (pronotum/elytra length ratio).

\section{Lasconotus niponius (Lewis, 1879)}

(Figs 1 and 5)

Xuthia niponia Lewis, 1879: 462.

Bitoma niponica: Nakane 1963: 218, pl. 109, fig. 18.

Bitoma niponia: Narukawa 2000: 1, pl. 1, fig. 1.

Lasconotus niponius: Ślipiński and Schuh 2008: 83; Aoki 2011: 77, figs 1, 2.

Lasconotus sp.: Aoki 2009a: 73, fig. 32A.

Material examined. 1 ex. (JAC-1), Isoyama Beach, Suzuka City, Mie Prefecture, Japan, 27 May 2010, J. Aoki leg. 1 ex. (JAC-2), the same place to JAC-1, 14 June 2008, N. Narukawa leg. 1 ex. (JAC-3), Shimin-no-mori, Kami-Yukawa-cho, Hakodate City, Hokkaido, Japan, 5 October 2015, K. Nagoshi leg. 1 ex. $\sigma^{\top}$ (JAC-4, dissected and mounted on slides), same place to JAC-1, 27 May 2010, J. Aoki leg.

Diagnosis. Body reddish or yellowish brawn, 1.90$2.40 \mathrm{~mm}$ in length; pronotum length $0.54-0.57 \mathrm{~mm}$; pronotum width $0.55-0.60 \mathrm{~mm}$; elytral length $1.40-1.53 \mathrm{~mm}$; elytral width $0.60-0.63 \mathrm{~mm}$; PW/PL 1.02-1.07; EW/PW 1.031.05; EL/EW 2.30-2.43; EL/PL 2.30-2.68. Terminal club of antenna consists of three larger segments, but ninth segment smaller than terminal two ones; third segment longer than fourth one (Fig. 1). Anterior angles of pronotum rounded; four conspicuous longitudinal carinae on pronotum; elytral ridges rather weak, ridges 3 and 4 joined together before reaching elytral edge. Sculpture on metasternum developed in lateral parts, but vanished in median part; sculpture on ventrites amoeba-like, irregularly connecting here and there (Fig. 5).

Variation. The specimens collected in Hokkaido tend to show two-color body, black (head and prothorax) and reddish (elytra) whereas the body color of specimens from the southern Japan is wholly brawn (somewhat darker on head and thorax than on elytra) (Aoki 2011). Except the body color, no differences are found between the Hokkaido group and the southern Japan group. Considering the isolated distribution (Fig. 12) of the two groups, they could represent different subspecies, but the only difference is body color with no taxonomical value.

Distribution. Japan: Hokkaido, Honshu (southwestern half), Shikoku and Kyushu.

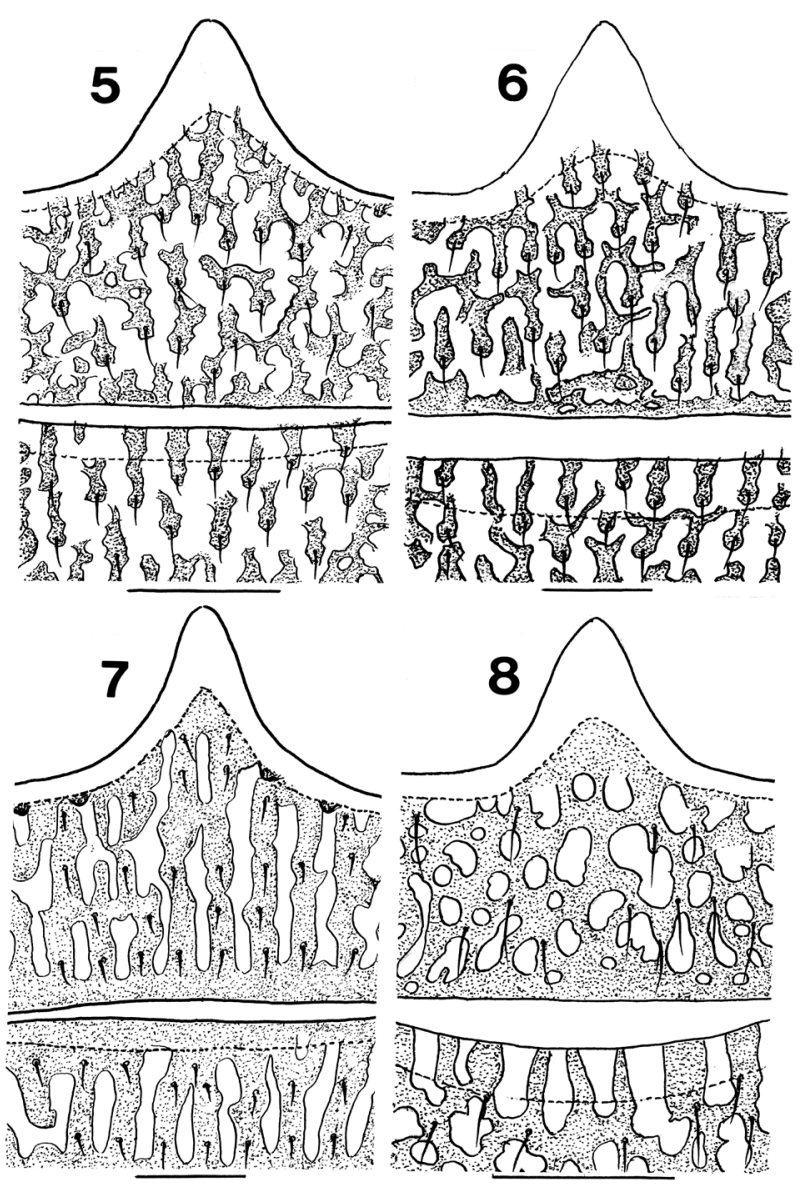

Figs 5-8. Anterior part of ventrites of the four Japanese species of Lasconotus. - 5, L. niponius (Lewis, 1879) (JAC-1); 6, L. okadai Aoki, 2011 (JAC-9); 7, L. sculpturatus (Sharp, 1885) (JAC-11); 8, L. akitai sp. nov. (paratype, NSMT-I-C 200239). Scale bars: $0.1 \mathrm{~mm}$.

Lasconotus okadai Aoki, 2011

(Figs 2 and 6)

Bitoma niponia (not of Lewis, 1879): Sasaji 1985: 292, pl. 48, fig. 1.

Lasconotus niponius (not of Lewis, 1879): Aoki 2009a: 124, fig. (p. 125) (in part).

Lasconotus okadai Aoki, 2011: 99, figs 3, 4; Aoki 2012: 45, fig. 33, 33A, 33B; 2013a: 109, fig. 30; 2013b: 75, fig. 2-37C and D.

Material examined. 1 ex. (JAC-5), Institute of Nature Study, Shirokane-dai, Minato-ku, Tokyo, Japan, 17 May 2012, J. Aoki leg. 1 ex. (JAC-6), Sôgawa-mura, Gihu Prefecture, Japan, 22 June 2003, N. Kanie leg. 1 ex. (JAC-7), Imperial Palace, Tokyo, Japan, 18 May 2011, J. Aoki leg. 1 ex. $\delta$ (JAC-8, dissected and mounted on slides), the same place to JAC-7, 22 July 2010, J. Aoki leg.; 1 ex. $\widehat{o}$ (JAC-9, dissected and mounted on slides), Tôno-sawa, Hakone-machi, Kanagawa Prefecture, Japan, 29 March 2010, J. Aoki leg.

Diagnosis. Body black, mat, $2.35-2.90 \mathrm{~mm}$ in length; pronotum length $0.63-0.77 \mathrm{~mm}$; pronotum width 0.70 $0.78 \mathrm{~mm}$; elytral length $1.70-1.88 \mathrm{~mm}$; elytral width 0.70 $0.80 \mathrm{~mm}$; PW/PL 1.01-1.07; EW/PW 1.00-1.03; EL/EW 

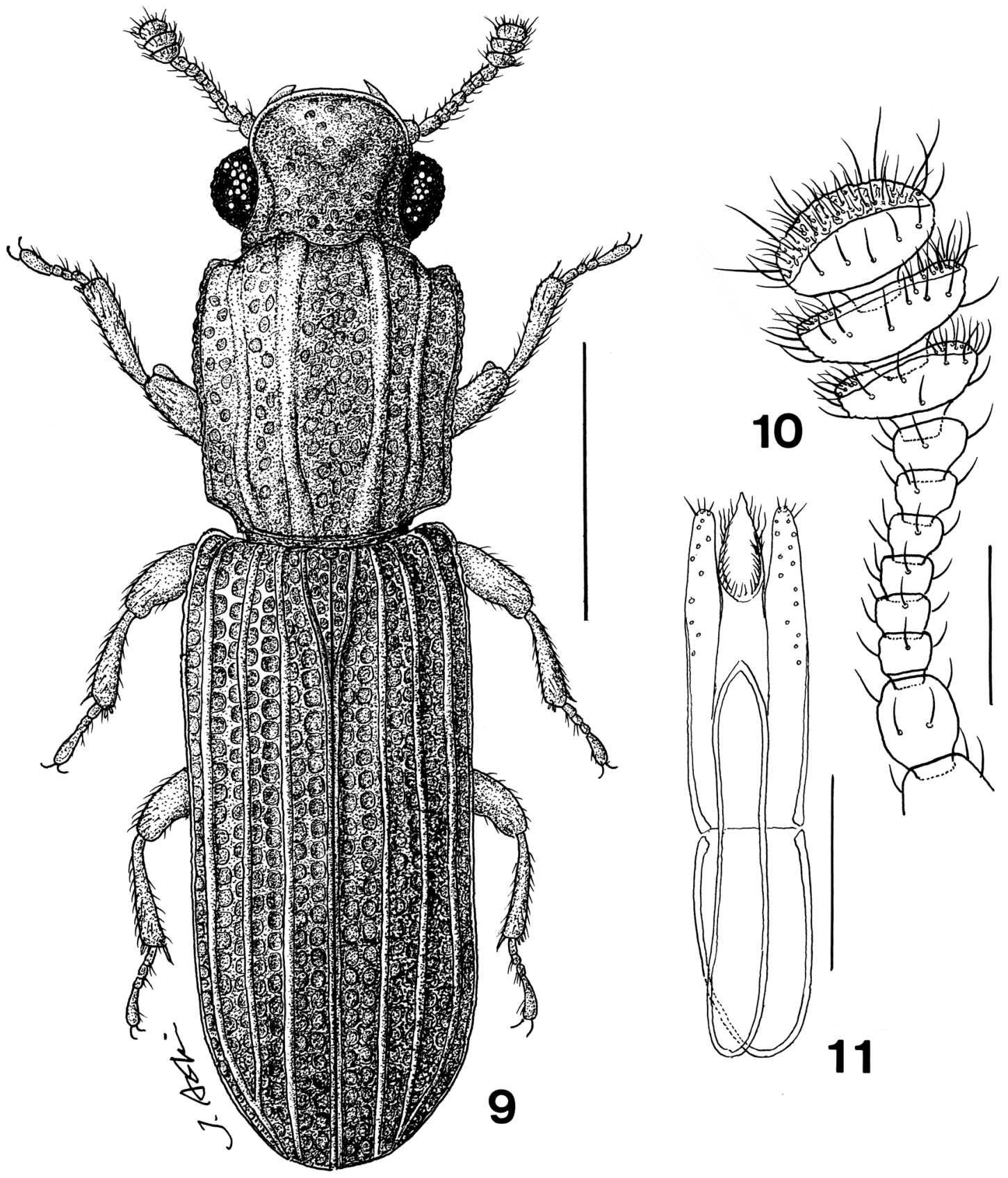

Figs 9-11. Lasconotus akitai sp. nov.-9, Habitus (holotype, NSMT-I-C 200237); 10, antenna (right side) ( paratype, NSMT-I-C 200238); 11, aedeagus (paratype, NSMT-I-C 200239). Scale bars: $0.5 \mathrm{~mm}$ for $9 ; 0.1 \mathrm{~mm}$ for $10,11$.

2.27-2.43; EL/PL 2.53-2.76. Terminal club of antenna consisting of three segments almost equal in size; third segment longer than fourth one (Fig. 2). Anterior angles of pronotum usually produced, but not so prominently and sometimes rounded; among four longitudinal carinae on pronotum, two admedian ones broad and dull; elytral ridges strong, ridges 3 and 4 joined together before reaching elytral edge. Sculpture on metasternum wholly developed; sculpture on ventrites amoeba-like, irregularly connecting one another (Fig. 6).

Distribution. Japan: Hokkaido, Honshu and Kyushu.

\section{Lasconotus sculpturatus (Sharp, 1885)}

(Figs 3 and 7)

Ithris sculpturata Sharp, 1885: 72, pl. 3, fig. 4.

Lasconotus sculpturatus: Löbl and Smetana 2008: 83; Sasaji 1985: 219 (key); Aoki 2009a: 7, fig. 10; 2009b: 126, fig. (p. 127).

Lasconotus sculptratus : Aoki 2012: 47, fig. 34, 34A, 34B; 2013a: 109, fig. 28.

Material examined. 1 ex. (JAC-10), Nara Park, Nara City, Nara Prefecture, Japan, 3 June 2017, T. Ito leg. 1 ex. $\widehat{\sigma}$ (JAC-11, dissected and mounted on slides), Koseda-rindô, Kami-Yaku-cho, Yaku Island, Kagoshima Prefecture, Japan, 
- L. niponius

\ L. okadai

- L. sculpturatus

ㄴ. akitai

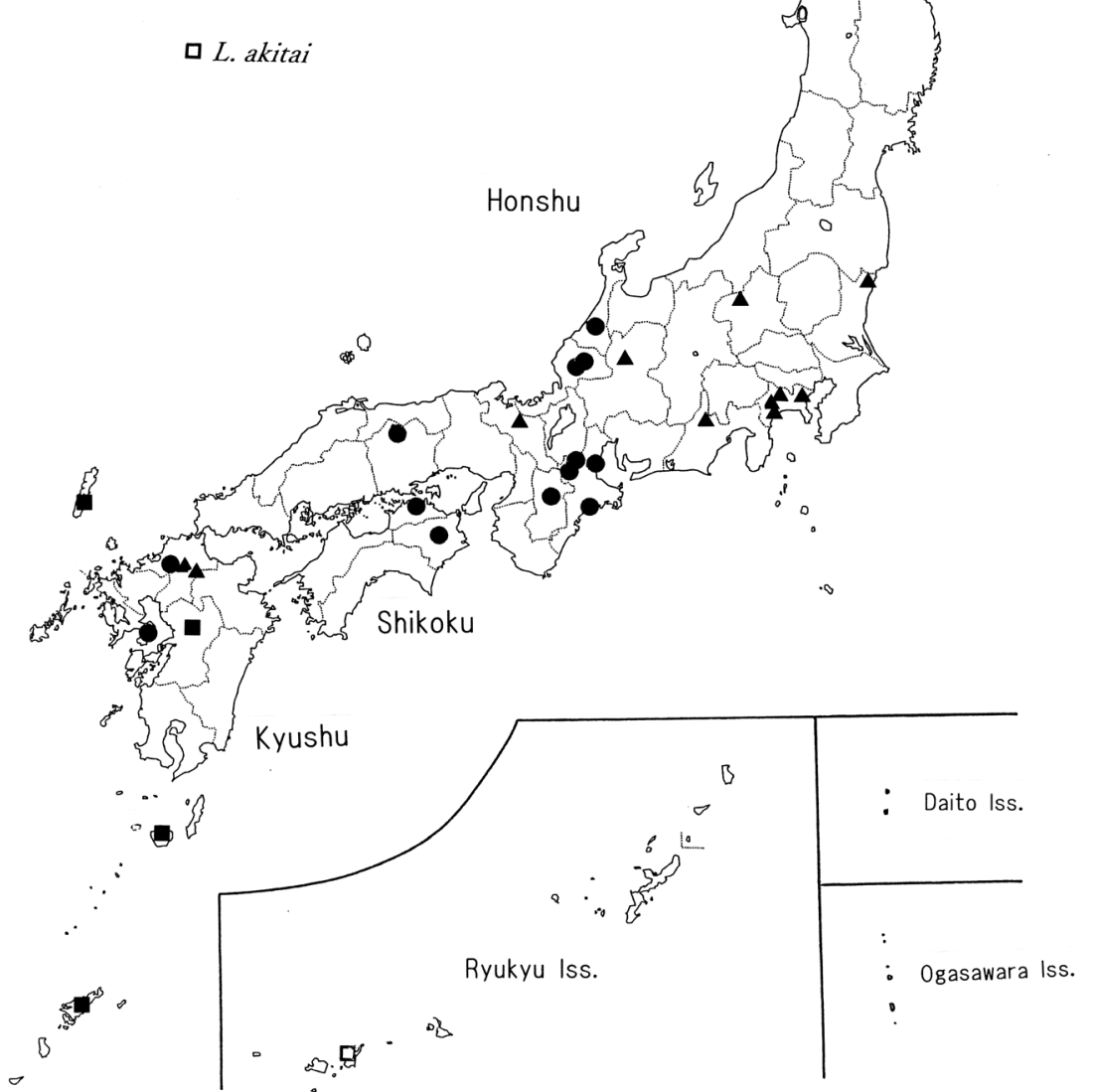

Fig. 12. Distribution map of the four Japanese species of Lasconotus based on the collection data in Nakane (1963), Sasaji (1985), Narukawa (2000), and Aoki (2009a, b, 2011, 2012, 2013a, b).

\section{July 2007, K. Hosokawa leg.}

Diagnosis. Body black, glossy, $2.70-2.85 \mathrm{~mm}$ in length; pronotum length $0.64-0.72 \mathrm{~mm}$; pronotum width $0.77-0.89 \mathrm{~mm}$; elytral length $1.67-1.95 \mathrm{~mm}$; elytral width 0.80-0.95 mm; PW/PL 1.21-1.27; EW/PW 1.04-1.07; EL/ EW 2.00-2.25; EL/PL 2.60-2.71. Antenna slender, terminal club consisting of three segments almost equal in size; third segment distinctly longer than fourth one (Fig. 3). Anterior angles of pronotum well produced, but not pointed at tip; front margin concave medially, four longitudinal carinae distinct and sharp, sublateral carinae nearly straight, admedian ones strongly sinuate; elytral ridges sharp and conspicuous, ridge 4 strongly inflated in apical part, ridges 3 and 5 vanishing apically. Sculpture on metasternum wholly developed; sculpture on ventrites irregular longitudinal stripes, connecting here and there (Fig. 7).

Distribution. Japan: Kyushu, Tsushima Island, Yaku Is- land, and Amami-Ôshima Island. Rare species.

\section{Lasconotus akitai sp. nov.}

(Figs 4, 8-11)

Type series. Holotype (NSMT-I-C 200237): Mt. Yarabu-dake, Ishigaki-jima island, the Ryukyu Islands, Japan, $24^{\circ} 25^{\prime} 20^{\prime \prime} \mathrm{N}, 124^{\circ} 5^{\prime} 42^{\prime \prime}, 24$ May 2010, K. Akita leg. Paratypes: 1 ex. (NSMT-I-C 200238), data same as in holotype; 1 ex. (NSMT-I-C 200239, dissected and mounted on slides), same data as in holotype; 1 ex. (NSMT-I-C 200240, dissected and mounted on slides), same data as in holotype; lex. (OMNH-TI ), place same as in holotype, 13 April 2016, S. Sugimoto leg. light trap; 1 ex. (MNMIn 9000005), data same as in holotype.

Description (the value in holotype presented in parentheses). Body length 1.52-1.90 (1.82) mm. Body yellow- 
ish brown, rather glossy. Pronotum length $0.44-0.52$ (0.48) $\mathrm{mm}$; pronotum width $0.40-0.51(0.51) \mathrm{mm}$; elytral length 1.00-1.20 (1.20) mm; elytral width 0.47-0.55 (0.55) mm; PW/PL 0.91-1.06 (1.06); EW/PW 0.98-1.08 (1.08); EL/EW 2.18-2.36 (2.18); EL/PL 2.27-2.53 (2.50). Sides of vertex raised and carinate, frons and vertex granulate, eyes large, half as long as their mutual distance, bearing thick facetal setae. Antenna rather short and thick, 11-segmented, antennal club consisting of terminal three segments of equal size, all transverse, last segment twice as wide as long; segments III and IV same in size (Figs 4 and 10). Pronotum, sides straight or slightly sinuate, parallel-sided or feebly narrowing posteriorly, four longitudinal carinae distinctly developed, admedian carinae nearly straight and parallel to each other, sublateral ones weakly sinuate, anterior and posterior angles distinct, nearly right angles; surface of pronotum covered with polygonal granules rather sparsely arranged. Elytra with distinct ridges, ridges 3 and 4 joined together before reaching elytral edge; sharply pointed setae arranged on ridges and intervals among punctures. Mesosternum, metasternum and abdomen ventrally covered all over with babble-shaped punctures of various shapes and sizes (Fig. 8 ), ventral setae long, about $0.13 \times$ the length of metasternum. Aedeagus (Fig. 11) trilobed-type, median lobe sharply pointed at tip, with fine hairs densely arranged on an elongate ring, parameres straight, each with four minute setae, 1.4 times as long as basal piece.

Distribution. Japan: the Ryukyu Islands (Ishigaki-jima island).

Etymology. The new species is named after Mr. Katsumi Akita who collected the specimens and offered them for my study.

\section{Key to the Japanese Species of Lasconotus Erichson, 1845}

1. Antennal club consisting of three larger segments (IX, X and XI) of equal size (Figs 2, 3, and 4); elytral ridges 3 and 4 not joining with each other apically; metasternum

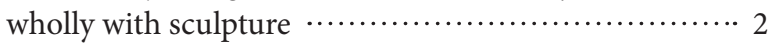

- Antennal club consisting of two larger segments ( $\mathrm{X}$ and $\mathrm{XI}$ ) and one medium-sized segment (IX); elytral ridges 3 and 4 joining with each other apically; metasternum lacking sculpture medially, only with hairs. Body length 1.90$2.40 \mathrm{~mm}$ L. niponius (Lewis)

2. Body color yellowish brown; terminal segment of antenna transverse; antennal segments III and IV equal in length; ventrites with sculpture of babble-like pattern (Fig. 8). Body length $1.52-1.90 \mathrm{~mm}$............. L. akitai sp. nov.

- Body color black; terminal segment of antenna rounded; antennal segment III more or less longer than IV; ventrites with sculpture of amoeba-like pattern (Figs 5, 6, and 7). Body length larger than $2.53 \mathrm{~mm} \ldots \ldots \ldots \ldots \ldots \ldots \ldots \ldots$

3. Body glossy; third elytral ridge strongly inflated in apical part to join with fifth ridge; fourth ridge vanishing apically; anterior margin of pronotum well concave medially. Body length 2.70-2.85 mm …... L. sculpturatus (Sharp)
- Body mat; third elytral ridge normal, not inflated in apical part, joining fourth ridge; anterior margin of pronotum weakly convex or slightly concave medially. Body length $2.35-2.90 \mathrm{~mm}$...................... L. okadai Aoki

\section{Discussion}

Pal (2007) described Lasconotus lushaicus Pal, 2007 from India which is very similar to L. akitai sp. nov. However, the latter differs from the Indian species in the following features (character states of L. lushaicus in parentheses): (1) smaller body size, i.e., $1.52-1.90 \mathrm{~mm}(2.80 \mathrm{~mm})$, (2) antennal segments III and IV same in shape and size (segments III elongate and longer than IV), (3) sublateral carinae on pronotum straight (sinuate), (4) elytral ridges 3 and 4 joining together apically ( 3 and 4 separated, 4 vanishing apically), and (5) parameres of aedeagus rather straight and parallel to each other (incurved apically). Among Japanese species (Aoki 2012, 2013a), L. akitai is readily distinguishable by the strongly transverse terminal antennal segments and the peculiar pattern of sculpture on the ventral plates.

\section{Acknowledgments}

I am greatly indebted to Mr. Katsumi Akita, a well-known taxonomist of the family Tenebrionidae, has always offered colydiine beetles for my study. He collected for this time an unknown species of this group and entrusted me for its taxonomical study. Mr. Takumi Saito sent me also one specimen of the same species collected recently by Mr. Shinji Sugimoto. I received comparable specimens of the other known species of Lasconotus from Mr. Takahisa Hirose, Dr. Hideto Hoshina, Mr. Koji Hosokawa, Mr. Tateo Ito, Mr. Noboru Kanie, Mr. Kazuo Nagoshi, Mr. Nobuyuki Narukawa, Dr. Keiichi Takahashi and Mr. Masataka Yoshida. I express my heartfelt thanks to the persons mentioned above.

\section{References}

Aoki, J. 2009a. [Colydiids. A Small Charming Group of Beetles, with Catalogue of the Japanese Species]. Tokai University Press, Tokyo. 194 pp. [In Japanese]

Aoki, J. 2009b. [The Japanese colydiids beetles not appeared in illustrated insect books]. Kanagawa-Chûhô, Odawara (165): 1-15. [In Japanese]

Aoki, J. 2011. Revised status of a colydiid species known as "Lasconotus niponius (Lewis)" (Coleoptera, Zopheridae). Elytra, N. S. 1: 97-102.

Aoki, J. 2012. [Cylindrical Bark Beetles of Japan. Families Bothrideridae and Zopheridae]. Ropponashi Entomological Books, Tokyo, 93 pp. [In Japanese]

Aoki, J. 2013a. [Colydiids. A Small Charming Group of Beetles, with Catalogue of the Japanese Species]. Tokai University Press, Hiratsuka. The second edition. 213 pp. [In Japanese]

Aoki, J. 2013b. [A sudden outbreak of a colydiid beetle caused by the death of Cornus controversa Hemsl. all at once.] Pp. 72-75. In: 
Hamao, S. and Matsuura, K. (Eds) A Natural Forest in Tokyo: Biodiversity and Abiotic Environment in the Institute for Nature Study. Tokai University Press, Hadano. [In Japanese]

Lewis, G. 1879. On certain new species of Coleoptera from Japan. Annals and Magazine of Natural History. Ser. 5 4: 459-467.

Löbl, I. and Smetana, A. 2008. Catalogue of Palaearctic Coleoptera. Vol. 5. Apollo Books, Stenstrup, 669 pp.

Nakane, T. 1963. Family Colydiidae. Pp. 218-219, pls. 109-110. In: Nakane, T., Ohbayashi, K., Nomura, S., and Kurosawa, Y. (Eds) Iconographia Insectorum Japonicorum Colore Naturali Edita, Vol. II (Coleoptera). Hokuryukan, Tokyo. [In Japanese]

Narukawa, N. 2000. Some records of colydiid beetles. Kita-Kyūshū no
Konchū 47: 4, pl. 2. [In Japanese]

Pal, T. K. 2007. Insecta: Coleoptera: Colydiidae. Zoological Survey India. Fauna of Mizoram, State Fauna Series 14: 307-312

Sasaji, H. 1985. Family Colydiidae. Pp. 291-295. In: Kurosawa, Y., Hisamatsu, S., and H. Sasaji, H. (Eds) The Coleoptera of Japan in Color. Vol. III. Hoikusha Publishing Co., Ltd., Higashiosaka. [In Japanese]

Sharp, D. 1885. On the Colydiidae collected by Mr. G. Lewis in Japan. Journal of Linnean Society, Zoology 19: 58-84, pl. 3.

Ślipiński, S. A. and Schuh, R. 2008. Zopheridae. Pp. 78-87. In: Löbl, I. and Smetana, A. (Eds) Catalogue of Palaearctic Coleoptera. Vol. V. Apollo Books, Stensrup. 